\title{
Embedding Sustainability in Education through Experiential Learning Using Innovation and Entrepreneurship
}

\author{
Lotfi Belkhir ${ }^{1}$ \\ ${ }^{1}$ W Booth School of Engineering Practice, Hamilton, Canada \\ Correspondence: Lotfi Belkhir, ETB 504, W Booth School of Engineering Practice, Hamilton ON, L8S 0A3, \\ Canada. Tel: 1-905-525-9140 Ext 26078. E-mail: Belkhir@mcmaster.ca
}

Received: November 20, 2014

Accepted: December 13, 2014 Online Published: January 21, 2015

doi:10.5539/hes.v5n1p73

URL: http://dx.doi.org/10.5539/hes.v5n1p73

\begin{abstract}
In this pedagogical study, we introduce the design and findings of a pilot study on the effectiveness of a new Engineering graduate course, "Total Sustainability Management", in teaching and learning sustainability, both at the cognitive and the management level. The design of an "arms-length" anonymized pre- and post-course questionnaires was driven by the course key objectives and adopted framework of sustainability competencies. The findings and questions raised from this pilot study inform the proposed design of further study and, more importantly, the development of a framework for teaching and learning - and thus measuring - sustainability in graduate, interdisciplinary Engineering education.
\end{abstract}

Keywords: sustainability learning, total sustainability management, TQM, innovation, entrepreneurship

\section{Introduction}

The departmentalized structure of post-secondary institutions along well-defined disciplines makes the effective teaching of an inherently trans-disciplinary subject, such as sustainability, a complex challenge. Nonetheless, this challenge is one that must be addressed urgently if we are to equip our students with the commitment and skills necessary to take on successfully this enormous task.

Our objective behind this course was to teach sustainability in an experiential way to seek to embed it into the students' minds as a foundational "way of thinking" rather than an additional requirement and "plug-in" burden. We chose to teach it within a commercial and innovation-based entrepreneurial setting, because we found on one hand that this setting provides all the multi-disciplinary elements of achieving sustainability in a complex organization with competing priorities, but also because innovation-based entrepreneurship provides the greatest opportunity, in our view, for disrupting the status-quo of the current unsustainable corporate legacy that is mostly responsible for the current state of affairs.

The terms sustainable entrepreneurship, environmental entrepreneurship and ecoproneurship are used inter-changeably, often meaning the development of environmentally friendly innovation or the creation of social enterprises.

In the reviewed literature the terms ecopreneurship and environmental entrepreneurship are used synonymously meaning innovative behavior of single actors or organizations operating in the private business sector which see environmental aspects as a core objective and competitive advantage. Ecopreneurs identify environmental innovations and their market opportunity and successfully implement these innovations resulting in new products or services (Lober, 1998; Pastakia, 1998). Another category of authors take the view that sustainable entrepreneurship is more a matter of strategy that is applicable to any and every business, along the same lines as Schaltegger (Schaltegger, 2002). In the Cradle-to-Cradle framework, McDonough and Braungart (McDonough \& Braungart, 2002) introduce a general manufacturing framework that progressively eliminates waste and enables raw material closed-loop reutilization indefinitely, hence enabling effective sustainable resource re-utilization. The Leeds School of Business at Colorado University created a "Deming Centre for Entrepreneurship" (Note 1) focusing on undergraduate education in entrepreneurship studies with a strong sustainability focus. It also offers a course on Sustainable Operations (MGMT4130) which consists of case studies, class discussions and research papers. Unlike this course, ours teaches sustainability using the paradigm of Total Quality Management, and focusing primarily on applying them within a commercial and entrepreneurial 
setting.

The challenge I try to address in this course is two-fold: (i) the first one is a cognitive challenge; namely to understand what sustainability in general, and for a commercial entity in particular, really means; and (ii) the second is how to manage sustainability within a commercial entity, and especially an innovation-based startup, as an innovation lens and a source of competitive advantage, rather than an operational burden.

The methodology we selected is the Total Quality Management approach, supplemented by the Cradle-to-Cradle framework, as well as a set of broad-level sustainability design principles, including bio-mimicry and modularity.

In order to test the course's effectiveness, we have conducted an "arms-length" pre and post-course study, in the form of a voluntary online questionnaire with anonymized data.

\section{Method}

In order to test our course's effectiveness, we have conducted two "arms-length" online questionnaires; one just before the course (pre-course study) and one right after the completion of the course (post-course study). To ensure the integrity and ethics of the study, we used the assistance of a teaching assistant to ensure the results of those questionnaires were completely anonymized, aggregated and delivered to the instructor, only after all the students grades were finalized and released. The pre-course study was important in assessing the prior level of students' knowledge of and commitment for sustainability to better assess the net impact of the course on the students after its completion. The study also received the approval of McMaster University Board of Ethics before the surveys were collected and the results were released to the instructor for analysis.

The questionnaires were designed essentially around two categories of information; (i) the self-assessment of the students about their cognitive and management levels of sophistication of sustainability before and after the course, and (ii) the aspects of the course that were the most effective and made the biggest difference in raising those levels.

In all, the pre-course online survey consisted of 16 questions; 8 of which related to the students' overall career objectives as an engineer, business acumen, teamwork skills and current understanding of what sustainability means. The second half of the survey probed their underlying reasons behind taking the course, their expectations from the course and its relevance to their future career.

In the post-course survey, the students were then presented with 19 questions; 9 of which related to their new level of understanding, commitment and preparedness in sustainability management, and 10 questions related to the impact of the course on those aspects, and how the course could further be improved.

\section{Participants}

The participants of the study were graduate-level engineering students from several departments. In fact, the instructor actively sought students from the widest cross-section of engineering disciplines to bring the trans-disciplinary nature of sustainability projects to the forefront.

The first cohort composition contained a total of 12 students, amongst which 6 were from the entrepreneurship and innovation program, 2 engineering physics, 2 Engineering design, 1 from Engineering in Public Policy and 1 attending faculty from the Bachelor of Technology (B. Tech) program.

\section{Application: New Course Design}

\subsection{Course Objectives}

The course's primary objectives were 3-fold:

- To enable the students to develop a holistic and multi-disciplinary approach to sustainability as it applies to business and industry.

- To enable them to learn and assess the sustainability practices of a given company and identify gaps and opportunities for improvement.

- To enable them to synthesize the material learned and apply it to a particular team-based project.

\subsection{Course Description}

The course was designed to teach sustainability with a "Deming Approach", adapting some of Deming's 14 points of quality to managing sustainability, such as "constancy of purpose", "new philosophy", "Cease Reliance on Reporting", "mandated training", "Drive out fears", and "Bring down barriers".

The course consisted of 3 major parts, which were delivered over 12 weeks, in 3-hour lecture format: 
- Sustainable Concepts \& Methodology: sustainability concepts, quantification of sustainability and general methodology.

- Innovation, Policy and Sustainable Design: Innovation and sustainable development, sustainable design principles and product development, and interplay between policy and innovation.

- Organizational Strategy \& Operations: Embedding sustainability into company values, business model, business strategy and the Team.

Table 1. Covered topics during the 12-week long course

\begin{tabular}{|c|c|}
\hline Session & Topics Covered \\
\hline 1 & $\begin{array}{l}\text { Introduction: Concepts background, triple bottom line, Five Sustainable Competencies, Life Cycle } \\
\text { Management, Key sustainability metrics, GRI reporting. }\end{array}$ \\
\hline 2 & $\begin{array}{l}\text { Innovation \& Sustainable Development: Sustainability as a lens to innovation and a competitive } \\
\text { advantage, Eco-effectiveness v. eco-efficiency; strong v. weak sustainability. }\end{array}$ \\
\hline 3 & $\begin{array}{l}\text { Sustainable Design Principles: Bill-of-Rights of the planet; Design impact measures, Natural design } \\
\text { concepts, e.g. bio-mimicry, robust eco-design, waste as input material, design for the environment, } \\
\text { resource efficiency, modularity, service substitution. }\end{array}$ \\
\hline $4 \& 5$ & $\begin{array}{l}\text { Measuring Sustainability: Quantification of environmental and social impacts; Introduction of Life Cycle } \\
\text { Management; BASF Eco-efficiency method; other methodologies. }\end{array}$ \\
\hline 6 & $\begin{array}{l}\text { Building sustainability into the product: Applying the design principles to product development; } \\
\text { cradle-to-cradle framework; supply chain management; project team dynamics; product certification and } \\
\text { authenticity; cost-benefit analysis using TBL as a lens. }\end{array}$ \\
\hline 7 & $\begin{array}{l}\text { Interplay between Innovation, Ethics and Policy: Ethics; Social responsibility; Role of Sustainability } \\
\text { Ethics in business and engineering; influencing public policy through eco-innovation and pro-active } \\
\text { community development; link between regulations and policies with science and technology. }\end{array}$ \\
\hline 8 & $\begin{array}{l}\text { Optimizing the TBL through the value chain; Increasing gross margin through efficient partnerships; } \\
\text { leveraging existing capacities and resources. }\end{array}$ \\
\hline 9 & $\begin{array}{l}\text { Business Strategy: Quantitative and qualitative sustainability criteria to drive strategy; Vision, mission } \\
\text { and values in light of the TBL; the Benefit Corporation. }\end{array}$ \\
\hline 10 & $\begin{array}{l}\text { Sustainability \& the Team: Role of organizational culture and change management; Human Resources } \\
\text { best practices, Top green engineering companies in Canada. }\end{array}$ \\
\hline 11 & $\begin{array}{l}\text { A Deming Approach to sustainability: Using PDCA (Plan-Do-Check-Act) cycle; Sustainability } \\
\text { management theory a la Deming; Change management. }\end{array}$ \\
\hline 12 & Class Presentations of team projects. \\
\hline
\end{tabular}

\subsection{Unique Aspects of the Course}

One unique approach of this course was the use of a workshop to develop the detailed syllabus of the course. The workshop was held off-site over the course of a half-day and involved fifteen participants from various engineering department, McMaster DeGroote School of Business, the Biology department as well as several C-level executives from local small, medium and large companies in the Hamilton area. In addition to a refined course outline that gained the enthusiastic consensus of all the participants, some of the added benefits of the workshop were also (i) a list of volunteered and suggested speakers; (ii) a list of meaningful and exciting projects; and a Total Sustainability Management (TSM) Community of Practice with long-term commitment from the participants and other community leaders.

The course was designed to be team and project-based. Accordingly, and as a result of the course workshop, the students were presented with nine (09) potential projects by several internal and external speakers and project owners. A 4-hour, student-led project selection and team formation session was held by the students shortly thereafter to enable them to select their project of interest and self-select into a team with other students that share a similar interest in their project of choice. The students were motivated to take this exercise seriously by requiring them to present the results of this session one week later in the form of a graded assignment 
committing the team and giving a brief overview of the project itself. Assignments were designed to lead the students to apply the learned material to their new venture project.

Finally, in addition to the instructor-led lectures and the team-based projects, another central component of the course was a set of outside speakers on the subjects of sustainability reporting; measurement of sustainability; eco-entrepreneurship; sustainable business models; sustainable business strategies and sustainable cultures.

\subsection{Structure of the Project Brief}

The Project Brief comprised the following five sections which helped provide a comprehensive framework for sustainability management within a commercially motivated venture:

The Problem: A concise statement of the project, proposal or problem. This section should explain in one paragraph the market need, the pain or the opportunity that the target problem presents. It sets out in the form of a question or a statement what the rest of the brief is about.

The proposed solution and benefits: Describes the solution envisioned and how it will solve that particular problem or meet that unfulfilled market need in a unique and/or novel way. It also states the added benefits (economic, social and environmental) that the solution brings. The novel solution presented does not have to consist of a new product, but could consist of a novel business model, design, or even policy.

The Market: Describe at a high-level the market size and features that the solution would target. Is it large enough and stable enough to justify the cost of development of the solution? Is the need severe enough to make the solution affordable to the client and profitable to the company?

The Competition: How is that market need currently being met? Who are the existing direct and indirect competitors and how is the new solution different? What is the competitive advantage and unique selling point of the proposed solution? Also, how will that competitive advantage be sustained over time? Is it a patent, a unique business model or a customer lock-in?

Sustainability: Finally, how is the proposed business more sustainable than the existing solutions? Is it in the problem that is solves, the solution it presents or the benefits it provides? How does the team intend to maintain and even improve that sustainability over time?

The Project Brief effectively creates a roadmap for the team to follow and deliver against, throughout the rest of the 12-week course, by using the material learned throughout the course and applying it to their specific project. As a final assignment counting for $40 \%$ of the course mark, the student team wrote a final project report as well as made a team presentation of 15 minutes. Both comprised the sections shown in Table 2. There was also a peer-to-peer evaluation of the individual contribution of each team member that was used to adjust the mark of the team assignments for each individual student.

Table 2. Final project detailed structure

\begin{tabular}{ll}
\hline Section & Details \\
\hline Introduction & Project background and why this project. \\
Value Proposition & $\begin{array}{l}\text { The problem being solved, the solution proposed and the benefits it realizes for the } \\
\text { customers. }\end{array}$ \\
$\begin{array}{l}\text { Where } \\
\begin{array}{l}\text { Sustainability } \\
\text { embedded }\end{array}\end{array}$ & $\begin{array}{l}\text { a. Is sustainability embedded in the problem, the solution or the benefits? } \\
\text { b. How is it embedded: incremental or radical and disruptive? }\end{array}$ \\
& $\begin{array}{l}\text { c. What design principles were used? If it's a hardware product, what level of } \\
\text { Cradle-to-Cradle certification can be achieved over time? }\end{array}$ \\
\hline
\end{tabular}




\begin{tabular}{|c|c|}
\hline $\begin{array}{l}\text { Describe your } \\
\text { commercial project }\end{array}$ & $\begin{array}{l}\text { a. Market analysis, including market size, addressable market with supportive market } \\
\text { research. }\end{array}$ \\
\hline & b. Unique selling proposition: how's your solution uniquely differentiated? \\
\hline & $\begin{array}{l}\text { c. Sustainable competitive advantage: a utility or a business process patent; a } \\
\text { defensible business model or a high-switching cost for the customers? }\end{array}$ \\
\hline & $\begin{array}{l}\text { d. Business Model: How will you generate revenue and profits? (e.g. sales of } \\
\text { product/service, direct sales or through channels), and what are the expected gross } \\
\text { margins? }\end{array}$ \\
\hline & $\begin{array}{l}\text { e. High-level description of the Product Development Plan, including timeline and } \\
\text { costs. }\end{array}$ \\
\hline $\begin{array}{l}\text { Sustainability } \\
\text { Competencies }\end{array}$ & $\begin{array}{l}\text { Evaluate the project through the Five Core Competencies of sustainability (i.e. 1- Triple } \\
\text { bottom line; 2-Tools \& Metrics; 3-Stakeholders; 4- Complexity; and 5- Sustainability } \\
\text { Ethics \& Responsibilities) }\end{array}$ \\
\hline Conclusion & $\begin{array}{l}\text { a. Is the project commercially viable? were you able to successfully embed } \\
\text { sustainability in an innovative and competitive way? }\end{array}$ \\
\hline & b. How important was innovation to achieving this outcome? \\
\hline & c. What are the remaining gaps and questions necessary to complete the project? \\
\hline
\end{tabular}

\section{Findings: Course Effectiveness \& Learning Impacts}

\subsection{Students Responses}

Figure 1 shows one measure of the course effectiveness, per the students' own ranking of the aspects of the course they benefited the most from. They could pick as many as possible from a total list of ten, without regard to the order they picked them in. Every choice selected counted as one without regard to what order in the list it appears. The top ranked aspect was the instructor's effectiveness (92\%) followed closely by an equal ranking of the role of Guest Speakers and the complementarity between the lectures and project to the student learning $(83 \%)$. In third position, $75 \%$ of the students believed that the course prepared them well for future sustainability projects.

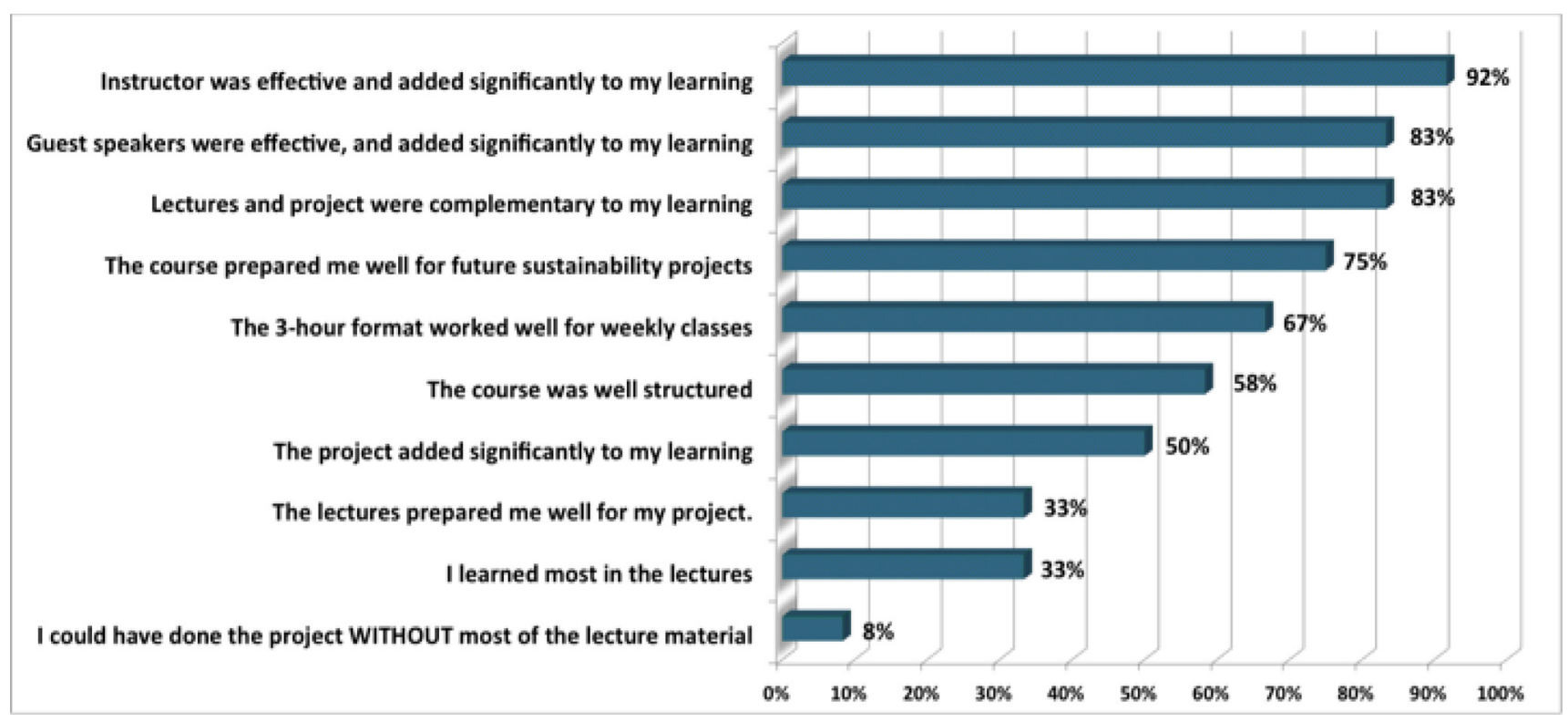

Figure 1. Percentage of students agreeing to one of ten aspects of the course without limitation to how many they can select 


\subsection{Impact on Cognitive and Management skills in Sustainability Management}

In Table 3, we show a normalized mean of the students' ranking of the impact of the course on various cognitive and management skills required in sustainability management. The students were asked to rank their answers from 1-5 in the first four questions, and from 1-7 in the last two questions of the list. We were quite pleased of the level of commitment the students displayed to sustainability management when most of them $(70 \%)$ did not even have a proper understanding of what sustainability meant at the beginning of the course.

Table 3. Normalized mean of students' assessment of various course benefits

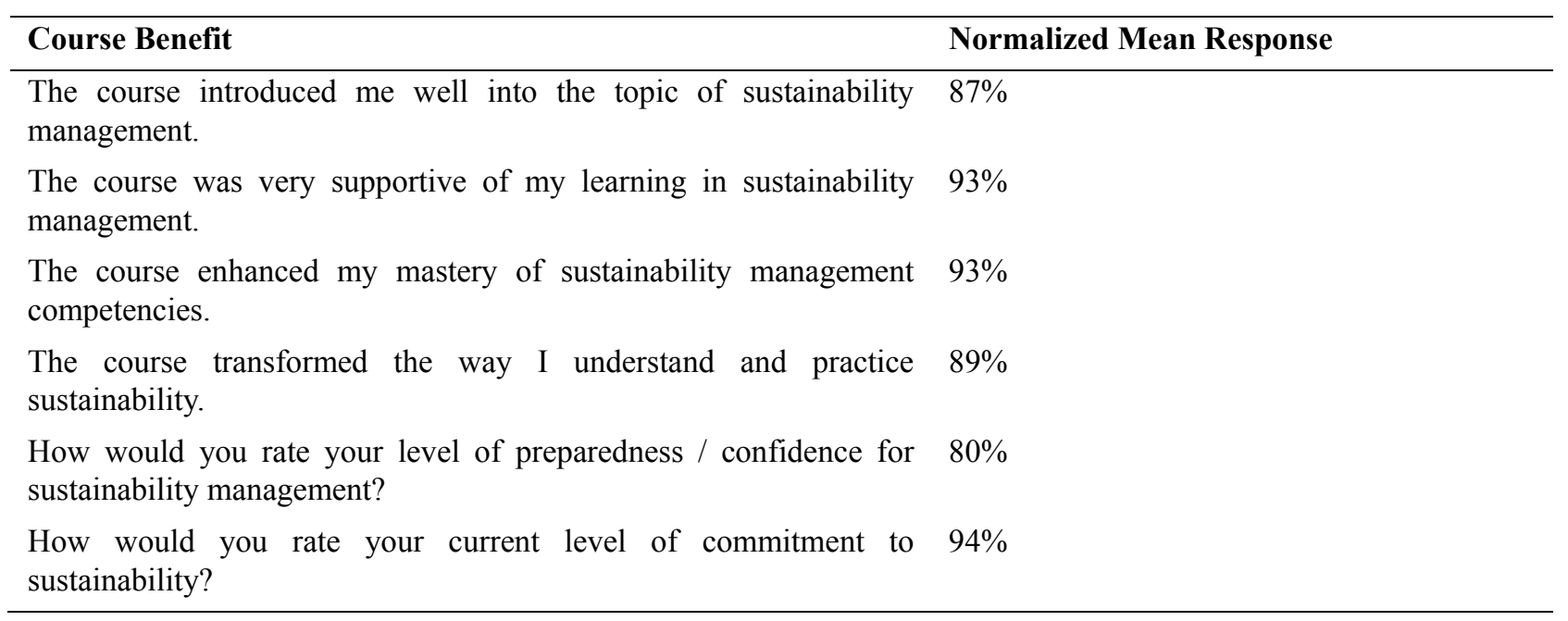

When asked which aspect of the course contributed the most to their increased commitment to sustainability, the students ranked the instructor as first, then the speakers and their project in third position (See Fig 2 below).

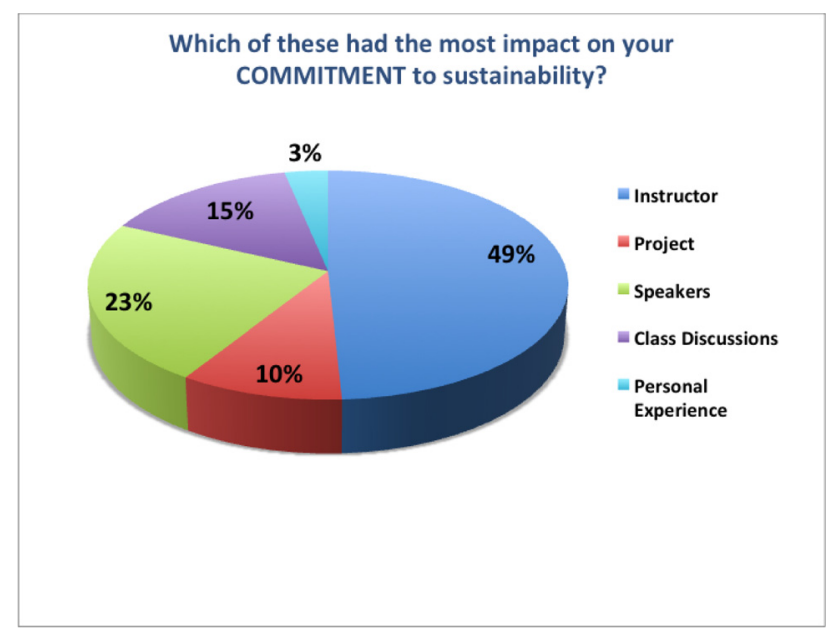

Figure 2. Relative impact of each course aspect on the students' commitment to sustainability

\subsection{In Students Words}

\subsubsection{The Take-Aways}

The participants were also asked to write the three major take-aways of the course from their perspective. Some of the most interesting ones were:

- Change will come from innovations not government policy. 
- Sustainable solutions don't need to have economic trade-offs; Sustainable solutions can lead to unmatchable competitive advantages; Sustainable solutions require thinking outside the box.

- This course was highly beneficial; it exposed students to the concept of sustainability from the economic sense as well as the traditional environmental and social. As someone who has worked in industry for close to ten years, I found this course in many ways enlightening. I intend on adopting many of the concepts wonderfully taught by Dr. Belkhir into my professional \& personal life moving forward. I would honestly say that [it] is the best course I have taken at McMaster and beyond.

- There are careers in sustainability, even if the job title doesn't include the word 'sustainable.' That is, it's possible to engage in sustainability in a wide variety of different fields.

- Sustainability takes into account the environment, people and economy. Thus, we need to embed sustainability in our products, business strategies and teams to optimize the three bottom lines (environment, economy, equity).

- That I will be a better citizen as a result of this course.

- Real companies exist that are achieving sustainable operations in all considerations (especially impressed by REfficient). (Note 2)

- Implementing sustainability to business does not require [more] money; It adds great value to business.

\subsubsection{Strengths \& Weaknesses}

The participants were also asked to list the strengths and weaknesses of the course.

Strenghts:

- Convincing, real-life businesses that demonstrate sustainability outside of the classroom.

- Diverse backgrounds of classmates and speakers were great learning and networking opportunities.

- Deming analogy is an interesting new perspective on how sustainability actually may be achievable.

- Supportive and approachable instructor who is passionate about sustainability.

- It has diversity that added strength to it; (it was) also very practical.

- Material and methodology.

- It helped me acquire a practical experience through the various speakers and understand sustainability through the project.

- Its comprehensive approach to sustainability.

- Very good guest speakers.

Weaknesses:

- Disconnect between work done on project and evaluations.

- As it was a new course so more material should be provided to students.

- Perhaps the course could have had a unifying theme that ran throughout the course...it showed up at the end with the Deming model but could have been interlaced into the weekly or biweekly discussions.

- Far less preparation or indication of business knowledge needed for reports and presentations than that provided on sustainability (although I understand that this is run through the W Booth School, for students taking this as electives this might be better addressed).

- Lack of ICT (Information \& Computer Technology) case studies.

- More examples/cases needed

- More assignments/practices about sustainability are needed.

\section{Discussion \& Next steps}

We have presented in this paper a pedagogical experiment of teaching sustainability a la Deming in the context of a commercial setting, and more specifically that of a startup. Based on an extensive anonymized survey of the inaugural cohort of students, the results exceeded our expectations and affirmed the fundamental hypothesis of the course, namely that (i) sustainability must be taught with an experiential, practical and holistic approach, and (ii) that a commercial, for-profit setting, is indeed a very appropriate context to expose the students to the 
multi-faceted, and multi-disciplinary nature of the sustainability challenge.

This course started as an elective course available to any graduate student enrolled in the Faculty of Engineering. The first edition of the course was taught in Jan-Mar 2013 to an initial cohort of 12 students. The enrollment then grew to 25 students the second time it was offered in Sept-Dec 2013 to students from the Entrepreneurship, Design and Public Policy programs. In a recent development, the faculties of the three programs have unanimously agreed to work to gradually make the course a core and mandatory module to be offered in Term 1 of the Academic year to all the entering students of the W. Booth School of Engineering Practice (Note 3).

\section{References}

Lober, D. J. (1998). Pollution prevention as corporate entrepreneurship. Journal of Organizational Change Management, 11(1), 26-37. http://dx.doi.org/10.1108/09534819810369554

McDonough, \& Braungart. (2002). Cradle to Cradle: Remakingthe Way We Make Things. North Press Point.

Mobley, C. L. (2013). Learning about sustainability: An interdisciplinary graduate seminar in biocomplexity. International Journal of Sustainability in Higher Education, 15(1), 16-33. http://dx.doi.org/10.1108/IJSHE-09-2011-0063

Moslemi, J. M. (2009). Training tomorrow's environmental problem solvers: An integrative approach to graduate education. BioScience, 59(6), 514-521. http://dx.doi.org/10.1525/bio.2009.59.6.10

Pastakia, A. (1998). Grassroots ecopreneurs: Change agents for a sustainable society. Journal of Organizational Change Management, 11(2), 157-173. http://dx.doi.org/10.1108/09534819810212142

Sarkis, J., \& Brust, D. V. (2010). Facilitating Sustainable Innovation through Collaboration-A Multi-Stakeholder Perspective. Springer. http://dx.doi.org/10.1007/978-90-481-3159-4

Schaltegger, S. (2002). A Framework for Ecopreneurship: Leading Pioneers and Environmental Managers to Ecopreneurship. Greenleaf Publishing.

\section{Notes.}

Note 1. http://leeds.colorado.edu

Note 2. REfficient is a local Hamilton-based company founded and led by Stephany McLarty; one of the speakers to the class. See www.refficient.com.

Note 3. The Entrepreneurship, Design and Public Policy Centres offer three distinct Master's degree programs and together, they make up the W. Booth School of Engineering Practice, which is part of the Faculty of Engineering.

\section{Copyrights}

Copyright for this article is retained by the author(s), with first publication rights granted to the journal.

This is an open-access article distributed under the terms and conditions of the Creative Commons Attribution license (http://creativecommons.org/licenses/by/3.0/). 